\title{
The metaphysical mind in its physical environment: Religious implications of neuroscience
}

\author{
C W du Toit \\ Research Institute for Theology and Religion \\ University of South Africa
}

\begin{abstract}
This article introduces ideas originating from different sciences of mind and the challenge they present to religion. In spite of overcoming the mind-body dualism, it seems that the mind-brain dualism still prevails. The mind-brain relation is discussed in the light of some models. Special attention is given to supervenient theories of mind. In light of this information the article investigates how the impact of these theories on religious experience. D'Aquili and Newberg's explanation of extraordinary religious experience is discussed. It is concluded that the phenomenon of religion and religious experience are more than mere brain functions. The place of religion and the continued importance of religion and religious experience are confirmed.
\end{abstract}

\section{INTRODUCTION: THEOLOGY AND SCIENCES OF MIND}

Sciences of mind have mushroomed since the 1990s. Three major fields include neuroscience, cognitive science and Artificial Intelligence. ${ }^{1}$ Cognitive science entails a

\footnotetext{
${ }^{1}$ Theories of consciousness are, however, not limited to specific disciplines. Philosophies of mind abound and provide a meaningful background to the debate. Of interest is the quantum mechanical approach which has recently become popular as a model to explain consciousness. According to Scott (1995:140), its attractiveness may stem from a law of minimisation of mystery according to which consciousness is mysterious and quantum mechanics is mysterious - since the two mysteries possibly have a common source. For Hodgson (1991:383-385) a strong indication of the close relationship between mental events and the development of quantum physical states is the element of nonlocality in both. Mental events bring together, nonsequentially, elements associated with spatially separated physical events, and are in that respect indifferent to spatial separation. It follows that mental events somehow span space, to enable the simultaneous experiencing of, and acting upon, matters associated with spatially separated physical events. According to the theory of relativity, (instantaneous) correlations can be effected between spacelike separated events only in the quantum world (see also Chalmers 1996:333-358).
} 
cluster of disciplines dealing with mental functioning: motor control, perception, recognition, language, memory and reasoning. ${ }^{2}$ One branch of cognitive science deals with computer modelling of mental processes (Murphy 1998:14). Other important fields of study include behavioural neuroscience which tries to understand the neurobiological substrates of behaviour while cognitive psychology deals, among other things, with human learning and memory. Arbib (1999:81) distinguishes brain talk, mind talk and spirit talk. Brain talk speaks of lesion data, anatomy, neurophysiology and neurochemistry. Mind talk speaks of intention, action, perception, consciousness, and responsibility. Together they are regarded as neuroscience embedded within cognitive science. Spirit talk is construed as mind talk or God talk, or as something that regards our identity as being rooted in our relation with God. Although these approaches can be distinguished, they cannot be separated. Mind-brain sciences must take the whole person in its environment and different contexts into account to avoid reductionism. This seems to be an unattainable task. Such is the nature of complex systems, and the human person embodies ultimate biological complexity. ${ }^{3}$ However, neuroscientific models for religious experience abound and challenge theologians to respond.

${ }^{2}$ Cognitive science, established in the 1970s, studies conceptual systems. These systems can be viewed as the cornerstone of rational functions. They include memory and attention, thought and language. Cognitive science states that reason is not disembodied, but arises from the nature of our brains and bodily experiences. Reason builds on and makes use of forms of perceptual and motor inference. Reason is a bodily function. Many of conceptual inferences are sensorimotor inferences. Reason is not seen as universal in the transcendent sense. It is largely unconscious, metaphorical and emotionally engaged (Lakoff \& Johnson 1999:4, 10, 20). Human categories are conceptualised in prototypes. Each prototype is a neural structure that permits us to do some sort of inference or imaginative task, relative to a category. To make sharp distinctions we develop essence prototypes, which conceptualise categories as if they were sharply defined (Lakoff \& Johnson 1999:19-20). The important contribution of cognitive science is that it denies that reality, divided into categories, exists independently of human minds and bodies. We impose a rational structure on the world. The world does not have a fixed category structure. Lakoff and Johnson (1999:77) identify a basic level of concepts that arises partly from our motor schemas and our capacity for image formation. Our brains are structured to project patterns from sensorimotor areas to higher cortical areas. The basic level is the highest level at which we have mental images that stand for the entire category (27). It is the level at which most of our knowledge is organised. Metaphysical realism seems to work at this level (29). They also distinguish color and spatial-relations concepts, which link up with the basic level concepts (see 23ff, 30ff). Since these concepts are about what the body does, namely perceive and move, they infer that the body actually shapes these concepts (39). The biological perspective and the focus on the importance of our sensorimotor systems, explain why our concepts sit so well with the way we function in the world (43). We acquire a large system of primary metaphors automatically and unconsciously simply by functioning in the most ordinary ways in the everyday world from our earliest years, and so we all naturally think using hundreds of primary metaphors $(47,59)$. The cognitive unconscious has the following properties: It is intentional, representational, propositional, truth characterising and causal (116-117).

${ }^{3}$ Given 100 billion neurons each with an average of 3000 connections, each human being has something like 100 trillion $\left(10^{14}\right)$ synaptic switches. 
The religious aspects of human culture are reduced by many scientists as brain functions under specific circumstances. For some, the mind has simply become brain. The human person and the experience of reality are seen from the perspective of brain functions. The concept of soul is replaced with that of mind, ${ }^{4}$ the experience of awe and mystery (Rudolph Otto's mysterium tremendum et fascinosum) are seen as brain functions, the experience of the transcendent, hearing voices from God, seeing angels, devils or UFOs, typical near-death experiences, and so on, can allegedly be explained as brain functions under certain circumstances. Is God really something that exists "out there", beyond and independent of us? Or is God merely the product of an inherited human perception, the manifestation of an evolutionary adaptation that exists exclusively within the human brain?

The way in which the brain is involved in religion is a topic at the frontiers of science. It is linked to the problem of how brain gives rise to any kind of consciousness, which is perhaps one of the biggest mysteries left for science to solve. Brain-mind studies have aptly been called a "mindfield". Although brain-mind studies have progressed far beyond the notorious Cartesian idea that the mind is transparent to itself, they lack a clear interdisciplinary terminology and reference system while confusing models and metaphors abound. ${ }^{5}$ The question is whether neuroscience, neuropsychology, cognitive science, philosophy and theology (including religious studies) can meet one another in a meaningful dialogue.

\footnotetext{
4 The soul-body dualism has been rejected by most theologians as part of the Platonic and Cartesian legacy. Instead, terms like "body", "soul", "spirit" are considered to overlap in their meaning and are used in a functional way to describe the phenomena of human existence. Anderson (1998:182). Similarly, "mind" cannot be seen to replace the traditional meaning of "soul" as a separate entity endowed with an eternal nature. For a thorough discussion of the theological development of the soul concept, see Brown, W S (et al), Whatever happened to the soul?

5 Apart from viewing the functioning of the brain as analogous to metaphor, it is important to note that multiple metaphors are used by neuroscientists to understand the working of the brain. Happel (1999:294295) mentions that neuroscientists speak of landscapes and maps, transmitters and receivers, keyboards, housing and rooms, mosaics, networks, machines, computing centres with inputs and output, and even scripts, drama, actors and audiences. Apart from viewing the human brain from the perspective of metaphor, the functioning of the brain itself could be seen as metaphorical. This presupposes not only the metaphoric nature of language, but also the metaphoric way in which humans interact with their environment. There are usually many ways open to solve a problem and a multiplicity of ways to respond to challenges and interact with people. Depending on circumstances, the role that specific value systems play, the level of personal creativity and the input of different examples and associations, the person acts in a unique way in each circumstance. This metaphoric style of living is what makes life interesting and unpredictable. Without the metaphoric way of living we would operate in much the same way as computers run their programs.
} 
Theology, a relative newcomer to the debate, is faced with fundamental challenges it cannot ignore. Arbib (1999:81) argues that we cannot approach theology without some sense of the intricacy of the human brain. The possibility exists that religion can be reduced to nothing more than brain chemistry. Arbib (1999:81), for example, believes that religious longing can be explained in terms of the physical properties of the brain. He sees theology as the study of those aspects of the human condition for which many have found God to be the answer. Neuroscience, and science in general, increasingly see God as noninterventionist - He does not capriciously change the laws of physics in response to prayer or to work miracles (Arbib 1999:100). In the science-religion debate the action of God in the world is increasingly linked to the natural order of physical reality. Peacock (1999:244ff) is a good example. Concerning the action of God on the level of the human brain he says that experiences of God often seem ineffable, incapable of description in terms of any other known experiences or by means of any accessible metaphors or analogies. Therefore it must be possible for God to influence these patterns of events in human brains which constitute human thoughts, including thoughts of God and a sense of personal interaction with God.

The point of departure of this article is that religion and religious experiences are a necessary product of human biological and cultural evolution. ${ }^{6}$ The universal appearance of religion in all its forms and functions proves this. Religion (including the

\footnotetext{
${ }^{6}$ Ashbrook \& Albright's (1997) work The humanizing brain, represents one of the astutest efforts to link brain functioning to Theism. They use the hypothesis that the human brain is the product of three major structural and functional developments, namely the reptilian, paleomammalian and neomammalian brain. The reptilian brain's major structure is the brain stem, the paleomammalian brain's major structure is the limbic system while the neomammalian brain includes the neocortex of humans. The functions of each of these structures are correlated with attributes of the Trinity, used as a suggestive analogue for understanding clues to God's way of being God (Ashbrook \& Albright 1997:51). According to Ashbrook \& Albright (1997:15), faith is built into the activity of our biology, our nervous system, our neurocognitive processes, our humanising brain. Ashbrook \& Albright $(1997: 44,127)$ hold that reality is mediated by the lens of the human. They acknowledge that this is an anthropomorphic approach (strongly criticised by Rottschaefer (1999:57-66), but suggest that their approach goes beyond anthropomorphism, since reality itself is humanlike - and any reality we perceive must of necessity be humanlike. Ashbrook (1989:78), states elsewhere that to use the brain as basis for analogical expression is, in fact, a metaphorical model of God. God is not the brain; yet brains are the most explicit clue to understanding God - more than body, more than lover, more than friend, more than father, more than rock. The attentional capacities and functions of the reptilian brain reflect the ever-present, unchanging character of God as well as God's eternity, omnipotence and immutability (Ashbrook \& Albright 1997:63-64). The limbic system of the paleomammalian brain (as well as the amygdala and hippocampus) mirror God's interactive, nurturing and persuasive character (Ashbrook \& Albright 1997:71-109). When coming to the neomammalian brain and the neocortex, the authors correlate the functions of the left brain and right brain respectively with God as the source of order and reason (left brain) and with God as relational (right brain) (Ashbrook \& Albright 1997:130; cf Ashbrook 1984:331-350). The frontal lobes, responsible for intentional activity are correlated with God as purposeful (Ashbrook and Albright 1997:132ff).
} 
myths and superstition often linked to it) seems to be indispensable to all humans. According to Teske (2001:93), human spirituality is a product of the very processes of human evolution which make the social construction of human culture, human meaning, and individual psychology possible. Brain-mind studies can help religious persons towards a better understanding of their religious experiences. The theological emphasis on the human person as a unity in relationships, can contribute to obviating reductionistic and simplistic approaches in the debate.

\section{THE MIND'S PROPENSITY FOR THE RELIGIOUS}

Human culture, as we know it has always been characterised by the awareness of the transcendent, inexplicable and mysterious. These transcendent experiences include, religious phenomena; visions and dreams; encounters with ghosts, angels, and demons; death and near-death experiences. Religion is unimaginable without an experience of divine revelation or one or other form of encounter with transcendent reality. These experiences are recorded in holy books, folklore and oral traditions and in mythologies of different cultures. From the dawn of our species, every culture - no matter how isolated - has believed in some form of a spiritual reality. Would this not imply that spirituality must represent an inherent characteristic of our species, that is, a genetically inherited trait? Are we. wired to believe in universal concepts like God, soul, and the afterlife? Are religious experiences the consequence of some divine action, or are they merely the effects of our brain's chemistry, a simple sensory hallucination that we interpret as being spiritual in nature? Recent studies show that such experiences can be traced to neural activity and can even be synthetically induced by electrically stimulating these specific portions of the brain.

Humans, and specifically the human brain, seemingly developed in such a way to display a propensity for the religious. The mind's propensity for the religious does not of necessity exclude the existence of God. Interaction with God through prayer, worship and ritual represent, is for most people, one of the ultimate experiences of reality. God can also be believed to have created humans through cosmological, evolutionary and biological history, as we understand it. 


\subsection{Evolutionary development and the biological rootedness of religion}

In recent studies, much has been written about the biological rootedness of rationality. ${ }^{7}$ In a similar vein, we can accept the biological rootedness of human emotions and experiences. Religion, like rationality, can be accepted as having a biological base.

Humans seem to have gained a strong religious aptitude through evolutionary development. They have been burying and presumably been weeping over their dead and preparing them for a journey to the Hereafter, for more than 100000 years. Joseph (2001:108) mentions that it is evident from Upper Paleolithic cave art that the nether world of the Cro-Magnon and other Upper Paleolithic peoples was haunted by the spirits and souls of the living, the dead, and those yet to be born, both animal and human. The preoccupation with the Hereafter, and the consequent evolutionary development of religions, seems natural if one presupposes that with the development of the neocortex and consciousness, a new awareness of time and space, self and other developed. The human environment changed dramatically, with the introduction of the awareness of time and space. A species arose who was challenged with questions such as the meaning of life (Where do we come from and where do we go after death? Why are we here?), the relationship between humans and world, the interpretation of dreams, and the question of causal relations, to mention but a few. It is unimaginable that a species who developed higher levels of awareness, should not begin to ask religious and philosophical questions. Humans were evolutionarily equipped to deal with the questions that inevitably accompany higher states of consciousness. A new world-view changes our environment dramatically. Humans as self-organising (autopoietic) beings develop new systems, structures, values, rules and interpretations to deal with a new environment. A new environment generates responses from the organism to deal with challenges posed by it. This is the development of cultural evolution. Typical of most religions is their will to

\footnotetext{
7 There is a growing realisation that human rationality, ethics, thought and consciousness, in fact all of human nature, must be related to its biological roots. Studies have appeared that link rationality to is biological roots (Van Huyssteen), to language and cognitive science (Lakoff, Johnston), and to neuroscience (Happel, Arbib). Evolutionary epistemology links human understanding with its biological roots and has implications for various disciplines, ranging from theology to psychology, sociology and of course epistemology. Evolutionary epistemology is a by-product of evolutionary biology and provides models for human self-understanding. It claims that the growth of knowledge is akin to the evolutionary growth of organisms. All knowledge is shaped and informed by certain innate principles which have influenced human thought because of their adaptive value. Recent studies on autopoietic systems seem to present fascinating examples of how knowledge and the human body are structurally related.
} 
self-preservation (the continuation of tradition and conservation of their values), their expansionist drives (history of missions), the defense of their values (religious wars, persecutions and martyrdoms). For Wilson (1998:280), religions are analogous to superorganisms. They have a life cycle, they are born, they grow, they compete, they reproduce, and in the fullness of time, most of them die. In each of these phases, religions reflect the human organism that nourishes them.

The capacity to find meaning and experience God was impossible before the development of the neocortex which provided the capacity for consciousness, language and morals. From a faith point of view it can be accepted that the evolutionary development of humans and the establishment of the cultural environment paved the way for religion and enabled humans to perceive and worship God. Changing world-views and different ways of finding meaning impacts on the way religion is practiced and the divine experienced. The way humans believe in God changes to suit the needs of each specific time.

The cultural environment leaves ample space for God to influence the mind of humans in a way truthful to their biological nature. Religion can be harmonised with our biological drives. Both genes and culturgens (cultural DNA, encoded in language, cultural artifacts and traditions) conserve what is typical of the species. Religion fits the basic drives of preservation and continuation. The basic tenets of Christian belief are not incompatible with the story of life as unfolding in evolutionary biology. The biological rootedness of religion does not exclude the reality of God. Rolston (1999:38), for example, considers God to be the explanatory dimension for which contemporary biology leaves ample space.

\section{MODELS OF THE MIND - BRAIN RELATIONSHIP}

There are many models trying to explain the mind-brain relationship. They vary from a reduction of mind to pure physicalism on the one side to substantialising mind as something separate from the physical on the other. Most popular and acceptable is the view that mind - brain forms a unity although mind is more that the mere physical. Some models will be dealt with and special attention given to supervenience theories of mind. But first, a few introductory remarks on brain and mind. 


\subsection{Brain}

The brain is determined by the neurochemistry of the body. Changes at the molecular level yield global changes in personality. Individual neurons, determined by their chemical make-up, contain one of many different neurotransmitters that are used for communication from one cell to another. Most brain-imaging techniques ${ }^{8}$ begin by taking an image of a persons' brain at rest to establish a baseline and then again during the performance of some activity called activation studies. Brain-imaging techniques are used to determine the various brain structures involved in different religious experiences. In the normal mode, everyday experience is that of time and matter, and the output of the brain is self-operative. Neural impulses normally follow certain pathways to produce the perceptions associated with our five senses and the movements of our muscles associated with the motor systems of the brain. But neural impulses can also travel a fundamentally different path through the same labyrinth of neural circuits. In this rare mode, senses, time, and movement lose their usual perceptual boundaries. This mode is called a state of Absolute Unitary Being (AUB), and is typical of a mystical, religious experience (Holmes 1993:204). This brings us to the question of mind and its independent ontological status.

\subsection{Mind}

In the context of this paper we understand mind broadly as consciousness (the having of thoughts, perceptions and feelings), awareness, soul, the seat of self-identity and selfunderstanding. Consciousness includes humans in all their relationships - their cultural, linguistic, religious and personal context which all contribute to the specific character of the stream of conscious experience. The complexity of mind as the hub of all factors making up the individual makes it so difficult to define, model or explain it. The mind

\footnotetext{
8 CAT scans (computerised axial tomography) make it possible to study correlations between abnormalities and behavior of people.

PET scans (positron emission tomography) enable research correlating localised brain activity with the performance of specialised cognitive tasks.

MRI scans (magnetic resonance imaging) provide more detailed pictures revealing locations of brain damage.

SPECT - Single photon emission computed tomography.

EEG - Electroencephalograph. Measures brain waves.
} 
can be viewed from, different angles: a psychological, ${ }^{9}$ phenomenological, philosophical, neurological or religious angle. Each approach has its own focus, language, and interests. Our present aim is to understand the nature of mind and the brain-body link. The mind is, however, never empty. An unbiased, objective approach to mind seems impossible.

Mental properties are epistemologically irreducible to physical ones. They emerge from physical properties and are dependent on them, but cannot be reduced to them (Peacock 1999:230). We cannot simply refer to the lower brain state level as physical and the higher brains state level as nonphysical. What we understand about neurologically organised matter is not sufficient to explain the manifestations of the mental or spiritual (Stoeger 1999:143, 135). The question is whether mind has an independent ontological status, or whether it is simply a brain function.

The tradition of empiricism with its focus on physically detectable reality views the metaphysical or transphysical, as transcendentalism. The post-Cartesian age is antidualistic and pro-integrationist. There is the possibility that mind-body integration may eventually favour a one-dimensional physicalism and materialism at the cost of the spiritual. It seems likely that in evolutionary biology, cognitive science and neuroscience, morality, spirituality, religion and values may be seen as coming from the physical below, and need not be ascribed to a transcendent cause (see Wilson 1998:261). But let us briefly look at some models of the mind-brain relationship:

- Dualism (Eccles, Popper)

Mind (soul) and body are separate entities. This accords with the Cartesian tradition. The person is seen as soul. John Eccles favoured dualism because he could not see any other explanation for mind other than the postulation of a nonmaterial mind or soul.

\section{- Holistic dualism}

The person is a composite of separable parts but is to be identified with the whole and is seen as a unity.

\footnotetext{
${ }^{9}$ Chalmers (1996:26-27) mentions some psychological notions for which the term. consciousness is used. They include: awakeness, introspection, reportabilty, self-consciousness, attention, voluntary control and knowledge.
} 
- Reductive materialism/monism (Paul Churchland, Sidney Shoemaker) Mind (soul) and brain are identical.

- Nonreductive physicalism (Nancy Murphy, Roger Sperry, John Searle)

This is a form of monism that stresses that the oneness or unity of reality is its essential aspect. The person is a unitary physical organism without a separate nonphysical soul, but not reducible to the physiology of cells or the chemistry of molecules. The complex functioning of humans in relationships gives rise to "higher" human capacities such as morality and spirituality (Post 1998:195). For Murphy (1998:128) we need not postulate anything beyond ordinary experience to account for our ability to stand in a conscious relationship with God. Nonreductive physicalism denies the existence of a nonmaterial entity, the mind (or soul) but does not deny the existence of consciousness or the significance of conscious states or other mental phenomena (Murphy 1998:130-131). Searle maintains that consciousness has ontological status. He rejects both dualism and materialism and accepts that consciousness is both a qualitative, subjective "mental" phenomenon, and at the same time a natural part of the physical world.

- Eliminative/reductive materialism (Jacques Monod, Richard Rorty, Francis Crick, Daniel Dennett)

The person is a physical organism, whose emotional, moral and religious experiences will all ultimately be explained by the physical sciences. For Crick, the mind is nothing but molecular biology. He believes that a complex system such as human consciousness can be explained by the behaviour of its parts and their interactions.

- Emergentist monism (Clayton 1999:209ff)

This asserts that only one kind of thing exists. There are no two substances like the Cartesian res extensa and res cogitans. The world is one and constitutes a distinct order. The person is a complexly patterned entity within the world, one with diverse sets of naturally occurring properties, each of which needs to be understood by a science appropriate to its own level of complexity (ontological pluralism). The multiple layers of explanation (explanatory pluralism) account 
for the physical, biological, psychological, spiritual and other dimensions of the human person.

\section{- Supervenient theories of mind}

The human mind is literally a metaphysical phenomenon. Like all metaphysics it is linked to the physical, but transcends it; it operates with physical concepts, uses denotative language, and accepts the physical environment, to construct a world that supervenes the physical.

The challenge is to combine the different aspects of the human make-up in order to explain how many brain networks cohere to constitute a personality. This is undertaken by computational neuroscience in which computational models provide the most efficient way that the complex, nonlinear interactions between different elements of one biological "level" can be made to fit the constraints of the next higher level (Arbib 1999:85-86).

Consciousness is a property of the physical brain. Consciousness, however, is not physical but real which means that not only physical entities are real. If this were not the case, consciousness would be an illusion. Physical and nonphysical entities are thus related in a peculiar way. ${ }^{10}$

Mental states supervene on brain states. A particular mental state, or a particular sequence of brain states, each of which is a necessary condition for a certain mental state, will not in general be completely determined by the brain states themselves but by constitutive relationships at the level of the mental states (Stoeger 1999:143-144).

\footnotetext{
${ }^{10}$ Murphy (1999:xi) alleges that every time a mind introduces new energy into the world an equal amount of energy departs, in some mysterious way, from the universe - that is to say, if we maintain the law of conservation of mass-energy. Both the physical world and the human brain can be seen as an interplay of matter and energy (Ashbrook \& Albright 1999:139). Stoeger (1999:134) believes that we have to include life, consciousness and mental capacity as possible properties of matter, or of entities with mass-energy, even though we do not yet understand the laws of nature that relate to these remarkable characteristics. It is especially the fact that mass-energy is highly organised in definite ways that brings Stoeger to this conclusion. Many inanimate systems have lifelike qualities. What is it that distinguishes genuine living organisms from merely lifelike systems? There is a nonmaterial something inside living organisms, something unique and, literally, vital to their operation. That something is not molecules, for they are not living things. Only a system of molecular processes, taken collectively, may be considered alive. The nonmaterial something is information, answers Davies (1999:30, 36, 40, 92, 61ff). Penrose (quoted by Clayton 1999:193) believes that there is no such than as a conscious substance, which is ontologically a different sort of thing from physical phenomena. The information operative in consciousness is, for example, different from the algorithmic kind found in genes.
} 
Physical explanations of thoughts, feelings and emotions should be distinguished from explanations of those ideas in their own terms and within their own interrelationship. Thoughts have an intentional ${ }^{11}$ quality (intentionality) - they are "eccentric" in the literal sense of being outside themselves, that is, focussed on things outside themselves.

"Supervenience"12 designates a dependent but generally irreducible relationship that higher-level states have with lower-level states or properties. Supervenience is a relation between two sets of properties: B-properties (high-level properties) and Aproperties (basic low-level properties). A-properties are usually the physical properties (brain and body in our context). They are enforced by a complete theory of physics which includes inter alia mass, charge, spatiotemporal position, the exertion of various forces and so on (Chalmers 1996:33). Chalmers (1996:35) distinguishes logical and natural supervenience. Natural supervenience is nomic or empirical supervenience. Logical supervenience is defined in terms of logical possible worlds. Biological properties, for example, supervene on physical properties. One could imagine a Bproperty that may be logically possible, but which could never occur in the real world since it is naturally impossible. Even God could not have created a world that was physical identical to ours, but biologically distinct.

Chemical properties are "supervenient" - or "supervene" - on physical properties, and mental states are "supervenient" on brain states (Stoeger 1999:142). Clayton (1999:199-ff) distinguishes between strong and weak supervenience. In strong supervenience, a direct and full relationship of dependence between the mental and physical is

${ }^{11}$ Intentionality comes to the fore in the affordance (or invitation) character of the human mind. Natural objects are invested with cultural meaning. They "appeal" to us in this cultural mode. This is expressed in the term "Aufforderungscharakter" (invitation character, aboutness) in which the things we experience tell us what to do with them. Affordances in the environment are offered by things like surfaces that can be stood upon, places that present opportunities (Sanders 1999:129; Clayton 1999:191). The environment within which affordances may be deployed is not only the perceptual environment, but the entire universe of potential action. The positive affordance of an object can be perceived whether or not the observer needs to take advantage of it. It offers what it does because it is what it is. Sanders (1999:131) sees affordances as fundamental ontological entities. They are ontologically prior to objects and events. All animals perceive affordances. Animals move through their worlds in a kind of attunement with affordances. Different animals show different degrees of complexity in appreciating the multiplicities of affordances available. As in contemporary quantum mechanics, the points of view are those of the observer and of the observed. Affordances stress the character of subjective reality and the different ways the world could be. Environments are organism-indexed parts of the world (Sanders 1999:133-135).

${ }^{12}$ Epiphenomenalism is similar to supervenient theories of mind. It is a theory that conscious mental life is a causally inconsequential, immaterial by-product of physical processes in the brain. The mental is something different and something more than its conditions of origin. 
accepted. The physical determines the mental in its emergence and in all its subsequent behaviour. Micro-properties determine completely the macro-properties. Mental properties are macro-properties. Weak supervenience accepts that although physical structures and causes may determine the initial emergence of the mental, they do not fully determine the outcome of the mental life subsequent to its emergence. The mental is dependent on but not reducible to physical causes. There are mental causes that are not themselves the product of physical causes.

But what is the nature of these independent thought processes? They cannot be nonphysical since no thought, awareness or form of consciousness has a nonphysical source. What seems to be important to weak supervenience is the acceptance of a level of thought that exists on its own, and in a sense comes from "above" - from "the outside" and which is not dependent on lower physical causes. The problem lies in the isolation of brain and mind. No form of life can be isolated from its environment. In the case of humans, the brain is adapted to serve a highly complex form of life in a complicated and ever-changing environment. Mind represents "conscious buffer" between a physically supported organism and the creative interaction with its environment.

What weak supervenience denies is that mental events or concepts are only physically based. It holds that mental events are of a different type to physical events. The reason for posing the more-than-mere-physical seems important in order to maintain the eminence of the human person and to make space for the physical independent interaction of God with the human person. It is, however, unnecessary to mystify brain functions in order to preserve the uniqueness and dignity of humans. I believe that it is possible to maintain the physical dependence of thought processes as well as their "soulful" and free character. It is similar to the distinction between the rules of a game and the game itself; or the notes of a Bach fugue and the improvised manner in which it is played. Although the rules of a game (notes of a fugue) are fixed (the physical), the game itself cannot be predicted (working of mind). In a sense, the game exceeds the rules of the game and the improvisation of a piece of music the musical score. The human brain may work according to physical rules but the interaction of the human person in a specific context under specific circumstances is open and free.

One can concur with the following statements of Clayton (1999:204ff): Mental predicates represent a type of property, not a new form of substance; mental causation does not involve the addition of new energy into physical systems; mental processing 
does not occur without concurrent physical activity; mental causation is not supernatural but natural. The case for emergent mental causation is not by itself a case for the existence of God, divine action, an eternal soul, or life after death. To introduce a "soul substance" to the mind would be to relinquish the debate between theology and neuroscience and places us back on the road of dualism.

\section{NEUROPSYCHOLOGICAL MODELS FOR RELIGIOUS EX- PERIENCE}

D'Aquili and Newberg propose a physicalist account of extraordinary religious experience. The amygdale, hippocampus and inferior temporal lobe appear to subserve and provide the foundations for mystical, spiritual, and religious experience and the perception, or perhaps hallucination, of ghosts, demons, spirits, and belief in demonic or angelic possession. According to Joseph (2001:1906), the commonality of the limbic system to all peoples might explain why belief in souls, spirits, haunted houses, angels or demons, and the capacity to have mystical experiences, including the sensation of being possessed by gods or devils, or hearing voices, is a worldwide phenomenon. He argues that the essence of God and of our living soul may be slumbering within the depths of the ancient limbic lobe, buried in the belly of the brain (Joseph 2001:107).

To follow the argument one has to be aware of some principles of brain organisation. It must be remembered that brain functions can be localised to a certain extent, but no one particular part of the brain is the site for one particular function (Newberg \& d'Aquili 2000:57). ${ }^{13}$ The brain is always creating. All the nerve and nerve connections change with every new experience (Newberg \& d'Aquili 2000:54). The brain receives all its input from the various sensory organs throughout the body and this input is dynamic and variable.

The two hemispheres of the brain represent two independent consciousnesses. The left hemisphere is associated with nonverbal awareness of the environment; visualspatial perceptual functioning; facial recognition; the maintenance of the body image; and the mediation of most aspects of emotionality. It also governs expressive speech, linguistic knowledge and thought; mathematical and analytical reasoning; and the temporal-sequential aspects of consciousness (d'Aquili \& Newberg 993:178-179). d'Aquili \& Newberg (1993:179-181) postulate four tertiary association areas (the inferior temporal lobe (ITL); the inferior parietal lobe (IPL); the posterior superior parietal lobe 
(PSPL); and the prefrontal cortex) which in relationship with the limbic system and under certain conditions may involve the genesis of various mystical states, the sense of the divine and the subjective experience of God.

The right parietal lobe plays an important part in generalised localisation and the sense of spatial coordinates per se, whereas the left PSPL exerts an influence with regard to objects that may be directly manipulated. Some neurons in the left PSPL and other neurons respond to stimuli just beyond arm's reach. The distinction between self and world may ultimately arise from the left PSPL's ability to judge these two categories of distance (d'Aquili \& Newberg 1993:182). The posterior superior temporal lobe helps us orient ourselves with respect to the rest of the world. The inferior temporal lobe neurons scan the visual field in order to alert the organism to objects of interest which are detected and fixated upon. The inferior parietal lobe (IPL) is an association area which maintains rich interconnections with the visual, auditory, and somatic association areas. The IPL is responsible for generating abstract concepts and relating them to words. It is involved in conceptual comparison; automatic ordering of conceptual opposites; the naming of objects the naming of categories of objects; and in higher-order grammatical and logical operations.

The limbic structures (hypothalamus, amygdale and hippocampus) control the sensation, modulation and expression of emotion. The hypothalamus seems to represent an extension of the parasympathetic nervous system into the brain stem. It is the trophotropic (energy conserving) system involved in the homeostasis of the organism. In contrast, the lateral hypothalamic structures seem to be an extension of the sympathetic nervous system, called the ergotropic (energy-expending) system, involved with "Fight or flight" responses, with sensations of fear or with sensations of positive emotions. The hippocampus seems to prevent emotional extremes and acts in a modulating and moderating fashion, both on the amygdale and hypothalamus. The hippocampus has primarily a quiescent function in that it helps to maintain baseline body functions via the hypothalamus and quiescent system (Newberg \& d'Aquili 2000:57). The amygdale (which is intimately connected to the hypothalamus) is primarily related to our arousal activities. It enables us to hear sweet sounds, recall bitter memories, or determine if something is spiritually significant, sexually enticing, or good to eat. According to Joseph (2001:112), it makes it possible to experience the spiritually sublime, is concerned with most aspects of emotion, and allows us to store affective experiences in our memory 
or even to re-experience them. The amygdale enables us to experience emotions such as love and religious rapture. Some individuals report communing with spirits or receiving profound knowledge from the Hereafter, following amygdale/temporal lobe stimulation or the abnormal activation thereof (Joseph 2001:113).

The prefrontal cortex receives afferent fibres from all sensory modes. It mediates images and complicated imaginal patterns. It provides the ability to plan and orients the individual to future behaviour. It is the seat of the will or of intentionality. According to Joseph (2001:113), the amygdale, hippocampus and temporal lobe are richly interconnected and appear to act in concert in mystical experience, including the generation and experience of dream states and complex auditory and visual hallucination, such as those possibly induced by LSD. Intense activation of the temporal lobe, hippocampus and amygdale has been reported to give rise to a host of sexual, religious and spiritual experiences, and chronic hyperstimulation can induce one to become hyperreligious or to visualise and experience ghosts, demons, angels, and even God, as well as to claim demonic and angelic possession or the sensation of having left one's body.

An aspect that is crucial to the neurophysiological model of mystical states is the concept of deafferentation which means that the neural input into a structure is "cut off". It can happen because of surgical cutting, a destructive tumour or inhibitory fibres from other nervous system structures. When significant deafferentation of a structure occurs, the cells within the structure begin to fire either randomly, or according to the "internal logic" of the structure. Almost all of the examples of functional deafferentation originate in the prefrontal cortex and are therefore "willed" or "intended" by the subject as can be seen in Theravada meditation and some Zen schools (d'Aquili \& Newberg1993:185-186).

It is important to note that extraordinary or alternate states of religious experience $^{14}$ should not necessarily be elevated above "normal" religious experiences. Although alternate states of religious experience require extraordinary conditions and involve some of the brain functions described above, theologically speaking, they do not provide special access to God. No special faculty is needed to experience religious realities. What makes the experience religious is a meaningful combination of ordinary experiences, under circumstances that make it apparent that God is involved in the event in a special way (Murphy 1998a:143). The venture to explain extraordinary or mystical experiences of any kind in terms of brain functions should not be seen to threaten the future of religion or the existence of God. 


\section{RELIGION - MORE THAN SIMPLY A BRAIN FUNCTION}

Religion, viewed from a neuroscientific or evolutionary perspective, remains tremendously important to humans. Without venturing into the philosophical question of realism one can agree with Küng (quoted by Kerr 1999:31ff) that the modern history of epistemology from Descartes, Hume and Kant to Popper and Lorenz has made it clear that the fact of any reality at all independent of our consciousness can be accepted only in an act of trust. It is consequently not strange to have nothing better than an act of trust on which to found our belief in the existence of God. There is no logically conclusive proof for the reality of reality; nor is there one for the reality of God. Belief in the existence of God is a basic decision. We usually assume that religious experiences come from outside ourselves, from God.

Thinking about the mind-brain relationship cannot occur without a holistic view of the human being in his/her environment. Personhood cannot be explained in isolation; nor can the phenomenon of mind and consciousness. ${ }^{15}$ Our brains have evolved primarily as organs of social cooperation and understanding, involving the construction of symbolic representation and the development of mechanisms to reach social agreement. Individual aspects of neurodynamics and neurochemistry cannot be properly understood without taking the societal aspects into account (see Teske 2001:102). Neuroscience alone cannot provide a complete account of human nature or human spirituality because many of the important characteristics of both mind and spirit are not only emergent properties of an individual's central nervous system but may also be social emergents, that is, properties of a number of individuals in interaction. Consequently Teske $(2001: 95,103)$ feels that it is a mistake to look for the origin and locus of religious and spiritual functions within the individual, since the cognitive functions on which they depend are themselves socially generated. It is the culture, the community, the family and other human relationships that differentiate and constitute our individual psychology and provide the emergent capacities for transcending its limitations. The role of the environment cannot be overemphasised. The replication of human culture also depends on the storage devices of institutional religion (Teske 2001:96).

\section{CONCLUSION}


Although a case can be made out that the mind is simply a brain product, this does not change the way humans experience themselves. We are usually unaware of the chemical processes of the brain, the influence our limbic and gland systems exert on us, and the sensory input we depend upon, to operate. In a similar way we don't experience ourselves as having bodies - we are our bodies. We 'have' our brains in the mode of consciousness.

Reality, as human reality, is a construction. Although the "real" exists "out there" each of us experience it according to our own context, expectations and inter-pretations. Although God may be part of this construction, He is not for one moment less real for the believer than physical reality is.

We love differently and experience God differently. Rationalising about love doesn't change its impact on us. Understanding pain, doesn't take it away. Explaining religious experience in terms of brain functions will not change the way people experience God. Religion, perhaps like love, is here to stay. Religion may be explained along with human evolution. It may have developed with the growth of human consciousness to help humans make sense of life. Even if this is the case, it doesn't falsify the existence of God or abolish religion. God might have chosen it to be this way.

Mind - brain studies emphasise the unity of the human person. It brought the biological rootedness of human rationality, of human experience and of religion under attention. It stresses the complexity and marvel of the human person. This should enhance our respect for life, especially in its religious dimensions as manifested in the great variety of religious experiences and interpretations of God among different cultures.

Reductionism in any form must be avoided. Religious experience is more than some brain functions. The absence of extraordinary experiences does not reflect on the integrity of one's faith. In spite of all models of brain-mind integration, life remains a mystery.

\section{Works consulted}

Anderson, R S 1998. On being human: Spiritual saga of a creature soul, in Brown, W S et al (ed), Whatever happened to the soul?, 175-194. Minneapolis: Fortress. 
Arbib, M 1999. Towards a neuroscience of the person, in Russell J R et al (ed), Neuroscience and the person, 77-100. Vatican City State: Vatican Observatory Publications.

Ashbrook, J B 1984. Neurotheology: The working brain and the work of Theology. Zygon 19(3), 331-350.

Ashbrook, J B \& Albright, C R 1997. The humanizing brain: Where religion and neuroscience meet. Cleveland: Pilgrims.

Barbour, I 1997. Religion and science: Historical and contemporary issues. San Francisco: Harper.

Barbour, I 1999. Neuroscience, artificial intelligence, and human nature: Theological and philosophical, in Russell J R et al (ed), Neuroscience and the person, 250-280. Vatican City State: Vatican Observatory Publications.

Brown, W S, Murphy, N \& Malony, H N (eds) 1998. Whatever happened to the soul? Minneapolis: Fortress.

Chalmers, D J 1996. The conscious mind: In search of a fundamental theory. New York: Oxford

Clayton, P 1999. Neuroscience, the person, and God, in Russell J R et al (ed), Neuroscience and the person, 181-214. Vatican City State: Vatican Observatory Publications.

Csordas, T J 1999. Embodiment and cultural phenomenology, in Weiss, G \& Haber, H F (ed), Perspectives on Embodiment: The intersection of nature and culture. New York: Routledge.

d'Aquili, E G \& Newberg, A B 1993. Religious and mystical states: A neuropsychological model. Zygon 28(2), 177-199

Davies, $\mathrm{P}$ 1999. The $5^{\text {th }}$ miracle: The search for the origin and meaning of life. New York: Simon \& Schuster.

Hagoort, P 1999. Human capacity for language communication, in Russell J R et al (ed), Neuroscience and the person, 41-56. Vatican City State: Vatican Observatory Publications.

Happel, S 1999. The soul and neuroscience, in Russell J R et al (ed), Neuroscience and the person, 41-56, 281-304. Vatican City State: Vatican Observatory Publications. 
Hodgson, S 1991. The mind matters. Oxford: Clarendon.

Holmes, R H 1993. Thinking about religion and experiencing the brain: Eugene d'Aquili's biogenetic structural theory of Absolute Unitary Being. Zygon, 28(2), 201-215.

Hoy, C D 1999. Critical resistance: Foucault and Bordieu, in Weiss, G \& Haber, H F (ed), Perspectives on embodiment, 3-23. New York: Routledge.

Johnson, M 1999. Embodied reason, in Weiss G \& Haber H F (ed), Perspectives on embodiment, 80-102. New York: Routledge.

Joseph, R 2001. The limbic system and the soul: Evolution and the neuro-anatomy of religious experience. Zygon 36(1), 105-135.

Kerr, F 1999. The modern philosophy of self in recent theology, in Russell J R et al (ed), Neuroscience and the person, 23-40. Vatican City State: Vatican Observatory Publications.

Lakoff, G A \& Johnson, M 1999. Philosophy in the flesh: The embodied mind and its challenge to Western thought. New York: Basic Books.

Murphy, N 1998. Human nature: Historical, scientific, and religious issues, in Brown, W S et al (ed), Whatever happened to the soul? 1-30. Minneapolis: Fortress.

Murphy, N 1998a. Nonreductive physicalism: Philosophical issues, in Brown, W S et al (ed), Whatever happened to the soul? 127-148. Minneapolis: Fortress.

Newberg, A B \& d'Aquili, E G 2000. The creative brain/The creative mind. Zygon, 35(1), 53-68.

Peacock, A 1999. The sound of sheer silence, in Russell J R et al (ed), Neuroscience and the person, 215-247. Vatican City State: Vatican Observatory Publications.

Post, S G 1998. A moral case for nonreductive physicalism, in Brown, W S et al (eds), Whatever happened to the soul? 195-212. Minneapolis: Fortress.

Rolston, H 1999. Genes, genesis and God: Values and their origins in natural and human history. Cambridge: Cambridge University Press.

Rottschaefer, W A 1999. The image of God of Neurotheology: Reflections of culturally based Religious commitments of evolutionary based neuroscientific theories. Zygon 34(1), 57-66.

Russell, R J et al 1999. Neuroscience and the person. Vatican City State: Vatican Observatory Publications 
Sanders, J T 1999. Affordances: An ecological approach to first philosophy, in Weiss G \& Haber H F (ed), Perspectives on embodiment, 120-141. New York: Routledge.

Scott, A 1995. Stairway to the mind. New York: Copernicus.

Stannard, R (ed) 2000. God for the $21^{\text {st }}$ Century. Philadelphia: Templeton.

Stoeger, W 1999. The mind-brain problem, in Russell J R et al (ed), Neuroscience and the person, 129-146. Vatican City State: Vatican Observatory Publications.

Teske, J A 2001. The genesis of mind and spirit. Zygon 36(1), 93-104.

Wilson, E O 1998. Consilience: The unity of knowledge. New York: Vintage.

Zohar, D \& Marshall, I 2000. SQ: Spiritual intelligence the ultimate intelligence. London: Bloomsbury. 